\title{
Produção de carne e caracteristicas da carcaça de cordeiros não castrados, castrados e induzidos ao criptorquidismo
}

\author{
Production of meat and characteristics of lamb carcass non- \\ castrated, castrated and induced to cryptorchidism
}

\author{
Hélio Carlos Rocha ${ }^{1 *}$; Maria Isabel Botelho Vieira ${ }^{2}$; \\ Rafael Streinstrasser Fonseca ${ }^{3}$; Leandro Oliveira da Costa ${ }^{3}$; \\ Dileta Cecchetti ${ }^{4}$; Rogério dos Passos Nadal'; Filipe dos Santos Rocha ${ }^{5}$
}

\section{Resumo}

\begin{abstract}
As características da carne de cordeiro são influenciadas por uma série de fatores, entre os quais a produção hormonal a nível testicular. Para estimar a influência sobre a produção e as características da carne, foram utilizados 24 cordeiros machos cruzas entre as raças Suffolk, Ile de France, Santa Inês e Texel em um delineamento completamente casualizado com três tratamentos e oito repetições. Todos os animais foram submetidos ao mesmo manejo e criados sobre pastagens de campo nativo em um sistema Voisin. Os tratamentos foram constituídos de animais não castrados, castrados e induzidos ao criptorquidismo. O peso vivo foi obtido ao nascimento e posteriormente, uma vez por mês para o controle do desenvolvimento corporal, e antes do abate. Após o abate foi tomado o peso da carcaça quente e 24 horas após, o peso da carcaça resfriada em câmara fria a $5^{\circ} \mathrm{C}$. Também foram obtidos os pesos das variáveis relacionadas à carcaça. Os resultados foram analisados através do GLM Procedure e as médias comparadas através do Teste de Tukey a 5\% de significância. Não houve diferenças na produção, nos componentes e nas características da carne e da carcaça ovina produzidas por cordeiros não castrados, castrados e induzidos ao criptorquidismo criados em condições de pastagem nativa e abatidos jovens.
\end{abstract}

Palavras-chave: Ovino, macho inteiro, castrado, criptorquida

\begin{abstract}
The characteristics of lamb meat are influenced by a series of factors, among which the testicular hormone production. In order to estimate the influence on meat characteristics, 24 Suffolk, Ile de France, Santa Inês and Texel crossbred lambs male, in a completely casualised delineation, with three treatments and eight repetitions. All animals were managed in the same way, pasture-raised and fed on native grass, in a Voisin system. The experiment treatments were constituted of non-castrated, castrated and cryptorchid animals. Live weight measurements were recorded at birth, once a month to assess body development and before slaughter. The warm carcass weight at slaughter and the 24 hours post-slaughter weight of the carcass cooled in refrigeration chamber at $5^{\circ} \mathrm{C}$ were recorded. Also, the weights of the variables related to the carcass were obtained. The results were analyzed using GLM Procedure and the means
\end{abstract}

\footnotetext{
${ }^{1}$ Engenheiro Agrônomo. Prof. Dr., Cursos de Agronomia e Medicina Veterinária da Universidade de Passo Fundo, RS. Brasil, Campus I, Bairro São José, BR 285, km 171. CEP 99001-970. Passo Fundo, RS. E-mail: helio@upf.br

2 Médica Veterinária, Prof ${ }^{a}$. Dr ${ }^{a}$ Curso de Medicina Veterinária da UPF, Passo Fundo, RS. E-mail: marisabel@upf.br

3 Aluno do Curso de Agronomia da UPF, Passo Fundo, RS. E-mail: steinrafael@hotmail.com; leandro.jari@gmail.com

4 Bel. Matemática, Prof ${ }^{a}$. Msc Cursos de Agronomia e Medicina Veterinária da UPF, RS. E-mail: cecchetti@upf.br

5 Aluno do Curso de Medicina Veterinária da UPF, Passo Fundo, RS. E-mail: nadalvet@yahoo.com.br; fsr_vet@hotmail.com

* Autor para correspondência
} 
compared by Tukey's test at the 5\% significance level. No differences in production were found in the components and in the characteristics of the ovine meat and carcass of non-castrated, castrated and cryptorchid lambs raised on pasture land, fed on native grass and slaughtered young.

Key words: Ovine, entire male, castrated, Cryptorchid

\section{Introdução}

A exploração da ovinocultura, baseada em raças produtoras de carne, tem experimentado um novo impulso, haja vista a crescente demanda do consumidor brasileiro por carne ovina de qualidade. O sul e o nordeste são as duas principais regiões onde estão os maiores efetivos ovinos do país (IBGE, 2009), com 4,6 e 9,2 milhões de cabeças, respectivamente. O rebanho gaúcho permanece com o viés da lã e da carne, produzido por animais considerados de duplo propósito, que tem nos ovinos da raça Corriedale, os mais representativos. Enquanto que, no nordeste, a ovinocultura está baseada na raça Santa Inês.

A região norte-nordeste do Rio Grande do Sul, conhecida com a mais tradicional produtora de grãos do estado, tem despertado para esta nova oportunidade de negócio que é a produção de carne ovina. Esta atividade, integrada com a tradicional lavoura de produção de grãos, com a fruticultura, a erva-mate e a bovinocultura de leite, possibilita uma nova interface na exploração dos recursos naturais disponíveis, especialmente na agricultura familiar (ROCHA; DICKEL; MESSINA, 2007).

O principal produto em um sistema de produção de carne ovina é o cordeiro, animal jovem com carne de coloração rosada, boa quantidade de gordura e um alto rendimento de carcaça (ROCHA; DICKEL; MESSINA, 2007). As proporções de músculo, ossos e gordura varia de acordo com a raça, idade e o sexo (AZEREDO et. al., 2005). A percentagem de músculo é maior em animais jovens, enquanto que a gordura é maior nos animais mais velhos, já o tecido ósseo, apresenta menor variação (OSÓRIO, et al., 1999a; SILVA SOBRINHO, 2001).

Os cordeiros machos são os preferidos pelos produtores devido ao maior ganho de peso e por apresentarem menor deposição de gordura na carcaça (BEERMANN; ROBINSON; HOGUE, 1995).

A castração é um manejo comum na criação, utilizado para melhorar a produção de carne ovina, permitindo desta forma, uma oferta regular ao longo do ano, além de atender as necessidades do mercado consumidor (PEREIRA, et al., 2002). O ato da extirpação dos testículos é realizado em cordeiros com quatro semanas de vida, utilizado bisturi ou anel de borracha colocado através de um elastrador. Já a indução ao criptorquidismo é o ato de deslocar os testículos para a cavidade abdominal, também conhecido como castração térmica ou castração parcial (AZZARINI et al., 2001).

A castração é uma prática relativamente comum nos sistemas de produção de ovinos, e diferentes técnicas têm sido empregadas na aplicação deste método, cada uma com suas vantagens e desvantagens, tanto sob o ponto de vista da aplicação do procedimento, como dos cuidados pós-operatórios. A recomendação da castração é para os animais que são mantidos no rebanho, seja para a produção de lã e/ou são abatidos com idade mais avançada, com o objetivo de fornecimento de carne durante o ano. Por outro lado, estudar o desempenho dos animais submetidos a diferentes perfis hormonais poderia fornecer informações para o manejo produtivo e sobre as características da carne.

O objetivo deste trabalho foi avaliar a produção e as características da carne de cordeiros machos produzido por animais não castrados, castrados e induzidos ao criptorquidismo, com a finalidade de gerar conhecimentos que propiciem melhores condições na produção de carne ovina. 


\section{Material e Métodos}

O ensaio foi conduzido em uma área de $77.343,18$ $\mathrm{m}^{2}$, sistematizada através de um projeto de Pastoreio Racional Voisin, com 85 piquetes de $810 \mathrm{~m}^{2}$ (30m x $27 \mathrm{~m})$, mais corredores e áreas de lazer. A composição de plantas na área tinha o predomínio das seguintes espécies de vegetais: quicuio (Pennisetum clandestinum Hochst. ex Chiov), trevo branco (Trifolium repens L.), grama forquilha (Paspalum notatum Fluegge), grama missioneira (Axonopus affinis), capim anoni (Eragrostis spp), azevém (Lolium multiflorum L.), tiffton 85 (Cynodon spp), brachiaria (Braquiaria decumbens Stapf.), aveia preta (Avena strigosa Schreb.) e outras espécies de menor importância.

Os cordeiros machos foram selecionados a partir de lotes nascidos nos meses de maio e junho de 2007 de um rebanho de fêmeas, cruzas entre as raças Suffolk, Ile de France, Santa Inês e Texel, desmamados aos setenta dias com peso similar e criados com idêntico manejo.

Os tratamentos foram sorteados às unidades experimentais as quatro semanas de vida dos cordeiros, e constaram de animais não castrados, castrados e induzidos ao criptorquidismo. $\mathrm{Na}$ castração tradicional foi utilizado um elastrador para aplicação do anel de borracha para a extirpação dos testículos dos cordeiros. Para a indução ao criptorquidismo foi utilizado um elastrador para aplicação do anel de borracha, colocada no saco escrotal do cordeiro após o deslocamento manual dos testículos até a cavidade abdominal.

Todos os animais foram pesados mensalmente para o acompanhamento do desenvolvimento corporal e do controle sanitário. Antes do abate dos animais foram realizadas as seguintes avaliações: peso vivo, conformação $(1=$ muito pobre a 5 = excelente), avaliação corporal $(1=$ fraco a 5 = excelente), comprimento corporal, perímetro torácico, altura na região das cruzes, altura da perna e compacidade corporal (PV/comprimento corporal) segundo metodologia proposta por Osório et al., 1998.

Ao final da etapa de campo que ocorreu aos 118 dias, todos os animais foram submetidos a jejum hídrico de 18 horas, abatidos e pesados obtendo-se o peso da carcaça quente (PCQ). O abate consistiu em suspender o animal pela pata traseira e perfurar a jugular com uma faca, deixando escorrer o sangue, sendo os animais inspecionados pelo Serviço de Inspeção Municipal. As carcaças após o abate permaneceram em câmara fria à $5^{\circ} \mathrm{C}$ por 24 horas, quando foram retiradas e pesadas, obtendose o peso da carcaça resfriada (PCR). A partir do peso vivo (PV) e dos dados da carcaça quente e fria foram calculadas os rendimentos verdadeiro (PCQ/ PV x 100) e comercial (PCR/PV x 100).

Foram separados e pesados os seguintes componentes do animal: pelego, cabeça, patas, coração, fígado, rins e língua.

$\mathrm{Na}$ carcaça resfriada foram tomadas as seguintes avaliações: conformação $(1=$ muito pobre até 5 = excelente), comprimento interno da carcaça (L), comprimento da perna, peso da paleta esquerda, profundidade do tórax, compacidade da carcaça $(\mathrm{PCR} / \mathrm{L})$ e estado de engorduramento (1 $=$ excessivamente magro até $5=$ excessivamente gordo). A paleta esquerda foi separada da carcaça e após ser pesada foi congelada $\mathrm{a}-18^{\circ} \mathrm{C}$.

Entre a $12^{\mathrm{a}}$ e $13^{\mathrm{a}}$ costelas da meia carcaça, na secção transversal do músculo Longissimus dorsi, foi tomada a espessura de gordura de cobertura e no músculo, a coloração subjetiva ( $1=$ rosa claro, 2 = rosa escuro, 3 = vermelho claro, $4=$ vermelho vivo e $5=$ vermelho escuro), o marmoreio $(1=\mathrm{sem}$ até $5=$ excessivo $)$ e a textura (1=muito grossa até $5=$ muito fina) (OSÓRIO et al., 1998).

Para descongelar, a paleta permaneceu em geladeira por um período de $24 \mathrm{~h}$ à $5^{\circ} \mathrm{C}$, até o seu completo descongelamento. Para a análise da cor foi utilizado o músculo Tríceps branquial e o colorímetro Sistem Cielab de Cor (marca Hunter 
Lab, modelo Colorquest II), com o uso de leitura diretamente no músculo, operando do sistema CIE (L*a*b*). O colorímetro foi calibrado com placa de cerâmica branca, e o iluminante utilizado foi o D65. O ângulo usado foi o de $10^{\circ}$, e o porte de $1 \mathrm{~cm}^{2}$. As medidas foram realizadas em quatro pontos diferentes da amostra, em ambos os lados. Da paleta esquerda foi separado e pesado o tecido ósseo, muscular e gorduroso.

O delineamento experimental utilizado foi o completamente casualizado com três tratamentos e oito repetições, totalizando 24 cordeiros. Para análise estatística dos dados foi utilizado o GLM Procedure e as médias comparadas através do Teste de Tukey a 5\% de significância.

\section{Resultados e Discussão}

Os animais iniciaram o experimento com 15,2 \pm $2,70 \mathrm{~kg}$ (média \pm desvio padrão) e encerraram 118 dias após, com 33,8 $\pm 6,17 \mathrm{~kg}$ de peso vivo (PV), apresentando um ganho de peso médio (GPV) de $18,6 \pm 4,83 \mathrm{~kg}$ e uma média diária de $0,160 \mathrm{~kg} /$ dia com uma amplitude de 0,082 a $0,228 \mathrm{~kg} /$ dia.

Os cordeiros não castrados, castrados e induzidos ao criptorquidismo apresentaram peso vivo e morfologia similares nas diferentes variáveis estudadas $(\mathrm{P}>0,05)$ (Tabela 1, 2 e 3$)$.

Tabela 1. Média e desvio-padrão de características produtivas e comerciais de cordeiros machos não castrados, castrados e induzidos ao criptorquidismo.

\begin{tabular}{|c|c|c|c|c|}
\hline Características & Não castrados & Castrados & Criptorquidas & $\operatorname{Pr}>\mathbf{F}$ \\
\hline \multicolumn{5}{|c|}{ avaliação in vivo } \\
\hline Peso vivo jejum $(\mathrm{kg})$ & $32,4 \pm 6,1$ & $30,7 \pm 6,4$ & $31,3 \pm 5,5$ & 0,8534 \\
\hline Ganho peso vivo (kg) & $18,5 \pm 4,9$ & $17,6 \pm 5,2$ & $19,4 \pm 4,8$ & 0,7851 \\
\hline Ganho peso vivo/dia (g) & $160,0 \pm 42,7$ & $152,4 \pm 45,0$ & $167,5 \pm 41,4$ & 0,7806 \\
\hline Avaliação corporal $^{1}$ & $2,81 \pm 0,46$ & $3,06 \pm 0,50$ & $2,63 \pm 0,52$ & 0,2258 \\
\hline Conformação $^{1}$ & $2,75 \pm 0,71$ & $2,88 \pm 0,99$ & $2,50 \pm 0,76$ & 0,6586 \\
\hline Altura cruzes $(\mathrm{cm})$ & $63,0 \pm 3,8$ & $61,1 \pm 3,7$ & $65,2 \pm 4,2$ & 0,1392 \\
\hline Altura perna $(\mathrm{cm})$ & $44,8 \pm 2,4$ & $44,6 \pm 2,7$ & $45,5 \pm 2,5$ & 0,3056 \\
\hline Compacidade $(\mathrm{kg} / \mathrm{cm})$ & $0,52 \pm 0,07$ & $0,49 \pm 0,08$ & $0,51 \pm 0,08$ & 0,6206 \\
\hline Perímetro torácico $(\mathrm{cm})$ & $80,3 \pm 4,4$ & $77,3 \pm 4,5$ & $78,5 \pm 5,0$ & 0,4490 \\
\hline \multicolumn{5}{|c|}{ avaliação na carcaça } \\
\hline Peso carcaça quente $(\mathrm{kg})$ & $15,5 \pm 3,7$ & $14,5 \pm 3,4$ & $14,9 \pm 3,2$ & 0,8625 \\
\hline Peso carcaça resfriada (kg) & $15,2 \pm 3,7$ & $13,8 \pm 3,6$ & $13,9 \pm 3,0$ & 0,6691 \\
\hline Rendimento verdadeiro (\%) & $47,4 \pm 3,6$ & $47,1 \pm 2,5$ & $47,3 \pm 2,2$ & 0,9825 \\
\hline Rendimento comercial (\%) & $46,6 \pm 5,5$ & $44,5 \pm 2,9$ & $44,2 \pm 3,0$ & 0,9825 \\
\hline Comprimento carcaça $(\mathrm{cm})$ & $61,8 \pm 4,6$ & $63,0 \pm 4,6$ & $61,8 \pm 2,1$ & 0,8104 \\
\hline
\end{tabular}

${ }^{1}$ avaliação subjetiva 
Tabela 2. Média e desvio-padrão dos componentes do peso vivo e da carcaça de cordeiros machos não castrados, castrados e induzidos ao criptorquidismo.

\begin{tabular}{|c|c|c|c|c|}
\hline Características & Não castrados & Castrados & Criptorquidas & $\operatorname{Pr}>\mathbf{F}$ \\
\hline \multicolumn{5}{|c|}{ avaliação dos componentes do peso vivo } \\
\hline Peso pele $(\mathrm{kg})$ & $3,131 \pm 0,58$ & $2,617 \pm 0,54$ & $2,646 \pm 0,40$ & 0,1037 \\
\hline Peso cabeça $(\mathrm{kg})$ & $1,860 \pm 0,21$ & $1,616 \pm 0,26$ & $1,795 \pm 0,32$ & 0,2054 \\
\hline Peso patas $(\mathrm{kg})$ & $0,950 \pm 0,123$ & $0,848 \pm 0,115$ & $0,865 \pm 0,056$ & 0,1272 \\
\hline Peso coração (g) & $160,0 \pm 30,4$ & $144,3 \pm 27,9$ & $149,3 \pm 18,0$ & 0,4842 \\
\hline Peso fígado $(\mathrm{g})$ & $588,7 \pm 137,5$ & $498,7 \pm 95,8$ & $531,2 \pm 66,1$ & 0,2387 \\
\hline Peso rins $(\mathrm{g})$ & $99,3 \pm 20,7$ & $101,8 \pm 18,7$ & $110,0 \pm 13,8$ & 0,4800 \\
\hline Peso língua $(\mathrm{g})$ & $89,3 \pm 12,9$ & $82,5 \pm 19,6$ & $85,6 \pm 10,1$ & 0,6540 \\
\hline \multicolumn{5}{|c|}{ avaliação da morfologia e sensorial da carcaça } \\
\hline Comprimento externo $(\mathrm{cm})$ & $60,7 \pm 3,7$ & $58,6 \pm 4,0$ & $59,8 \pm 2,7$ & 0,5009 \\
\hline Comprimento interno (cm) & $58,4 \pm 4,0$ & $56,5 \pm 3,8$ & $57,4 \pm 2,6$ & 0,5729 \\
\hline Comprimento perna $(\mathrm{cm})$ & $29,5 \pm 2,3$ & $28,8 \pm 1,8$ & $29,5 \pm 1,7$ & 0,7074 \\
\hline Profundidade tórax $(\mathrm{cm})$ & $26,4 \pm 2,1$ & $25,3 \pm 1,7$ & $25,6 \pm 1,8$ & 0,4996 \\
\hline Compacidade carcaça $(\mathrm{kg} / \mathrm{cm})$ & $0,26 \pm 0,05$ & $0,24 \pm 0,05$ & $0,24 \pm 0,04$ & 0,7887 \\
\hline Engorduramento $^{1}$ & $2,63 \pm 0,88$ & $2,44 \pm 0,82$ & $2,50 \pm 1,20$ & 0,9269 \\
\hline Coloração $^{1}$ & $2,31 \pm 0,96$ & $2,19 \pm 0,92$ & $2,00 \pm 1,07$ & 0,8176 \\
\hline Marmoreio $^{1}$ & $1,50 \pm 0,53$ & $1,63 \pm 0,52$ & $1,63 \pm 0,74$ & 0,8938 \\
\hline Textura $^{1}$ & $4,00 \pm 0,00$ & $4,00 \pm 0,00$ & $4,00 \pm 0,00$ & - \\
\hline
\end{tabular}

${ }^{1}$ avaliação subjetiva

Tabela 3. Média e desvio-padrão de características teciduais e de coloração da paleta de cordeiros machos não castrados, castrados e induzidos ao criptorquidismo.

\begin{tabular}{lcccc}
\hline Características & Não castrados & Castrados & Criptorquidas & Pr $>$ F \\
\hline Paleta fresca $(\mathrm{kg})$ & $1,483 \pm 0,416$ & $1,483 \pm 0,371$ & $1,543 \pm 0,293$ & 0,9309 \\
Paleta congelada $(\mathrm{kg})$ & $1,467 \pm 0,412$ & $1,461 \pm 0,372$ & $1,528 \pm 0,295$ & 0,9190 \\
Músculo $(\mathrm{kg})$ & $0,940 \pm 0,252$ & $0,928 \pm 0,238$ & $0,949 \pm 0,180$ & 0,9816 \\
Osso $(\mathrm{kg})$ & $0,316 \pm 0,075$ & $0,309 \pm 0,044$ & $0,337 \pm 0,047$ & 0,5965 \\
Gordura $(\mathrm{kg})$ & $0,211 \pm 0,104$ & $0,224 \pm 0,107$ & $0,241 \pm 0,100$ & 0,8422 \\
Coloração $\left(\mathrm{L}^{*}\right)$ & $44,456 \pm 3,57$ & $45,603 \pm 2,19$ & $45,583 \pm 2,05$ & 0,6287 \\
Coloração $\left(\mathrm{a}^{*}\right)$ & $15,052 \pm 4,34$ & $14,006 \pm 2,69$ & $14,920 \pm 1,95$ & 0,7727 \\
Coloração $\left(\mathrm{b}^{*}\right)$ & $14,597 \pm 1,91$ & $14,930 \pm 1,29$ & $15,166 \pm 0,36$ & 0,7022 \\
\hline
\end{tabular}

L* (luminosidade), a* (intensidade da cor vermelha) e b* (intensidade da cor amarela)

A limitação no ganho de PV encontrado no presente trabalho é recorrente para ovinos criados em pastagem nativa no sul do Brasil. Entre os fatores que exercem influências sobre o ganho de peso dos animais estão: genótipo, sexo, tipo de nascimento, nutrição e qualidade do cordeiro (OSÓRIO, et al., 1999b). Em relação a este assunto cabe salientar que cordeiros abatidos muito jovens, machos e fêmeas, criados em condições de pastagem nativa, podem não apresentar diferenças em diversas características, como peso da carcaça quente, peso da carcaça resfriada e rendimento de carcaça (CARVALHO et al., 1999).

Azeredo et al., (2005), trabalhando com cordeiros da raça Corriedale não castrados, castrados e criptorquidas abatidos aos 120, 210 e 360 dias, não encontraram efeito para peso da carcaça quente e demais componentes do peso corporal quando compararam os diferentes tratamentos. 
Ribeiro et al., (2003), não encontraram diferenças quando compararam diferentes métodos de castração (burdizo, borracha e faca) com animais inteiros cruzados Hampshire Down, Ile de France e Suffolk, abatidos entre 30 e $32 \mathrm{~kg}$ de peso vivo. As médias para ganhos de peso foram $0,179 \mathrm{~kg}$ (inteiros), 0,177 kg (burdizzo), 0,170 kg (borracha) e $0,147 \mathrm{~kg}$ (faca).

Osório et al., (1999a), não verificaram efeito da castração sobre a produção de carne e demais características in vivo e da carcaça, quando compararam cordeiros cruzas Corriedale $\mathrm{x}$ Hampshire Down, castrados aos 45 dias de idade e criados em condições extensivas de pastagem natural.

Rocha et al., (2007), trabalhando com cordeiros criados em campo nativo, sem suplementação alimentar, relataram ganhos de peso vivo similares entre os genótipos Ile de France $(0,153 \mathrm{~kg} / \mathrm{dia})$, Texel $(0,154 \mathrm{~kg} / \mathrm{dia})$ e Cruzas $(0,153 \mathrm{~kg} / \mathrm{dia})(\mathrm{P}>0,05)$, no entanto, o rendimento de carcaça foi maior na raça Texel $(41,78 \%)$ quando comparado com a raça Ile de France $(40,37 \%)(\mathrm{P}<0,10)$.

Klein Jr., Siqueira e Roça (2008), trabalhando com cordeiros mestiços Ideal castrados e não castrados em fotoperíodos curto e longo, abatidos aos $37 \mathrm{~kg}$ de peso corporal, encontraram maior quantidade de gordura total nos animais castrados e mais tecido conjuntivo nos não castrados. No entanto, não houve diferenças no peso da paleta completa, do músculo, da gordura subcutânea, da gordura intramuscular e de osso.

Rota et al., (2006), não encontraram efeito da interação castração $\mathrm{x}$ idade de abate para cordeiros Corriedale castrados e não castrados criados em condições extensivas de pastagem natural e abatidos em diferentes períodos. No entanto, o efeito da castração foi significativo para o componente de cor L* (luminosidade).

O peso médio da carcaça quente (PCQ) foi de $14,9 \pm 3,36 \mathrm{~kg}$ e para o peso de carcaça resfriada (PCR), obtida após 24 horas em câmara fria $\left(5^{\circ} \mathrm{C}\right)$, foi de $14,3 \pm 3,40 \mathrm{~kg}(\mathrm{P}>0,05)$. A quebra média de peso da carcaça pelo resfriamento foi de $4,45 \%$. A pontuação média da avaliação corporal foi de 2,83 $\pm 0,50(\mathrm{P}>0,05)$ sendo que os animais castrados apresentaram maior valor absoluto. Resultados semelhantes foram relatados por Osório et al., (1999b), Pereira et al., (2002), Azeredo et al., (2005), trabalhando com cordeiros da raça Corriedale castrados e não castrados.

As variáveis, comprimento corporal e perímetro torácico, não apresentaram diferenças entre os tratamentos $(\mathrm{P}>0,05)$. A compacidade média foi de $0,50 \pm 0,08(\mathrm{P}>0,05)$, enquanto que a altura nas cruzes, nas pernas, peso da cabeça, de patas, do pelego, do coração, dos rins, do fígado e da língua também não apresentaram diferença significativa entre os tratamentos $(\mathrm{P}>0,05)$, concordando com os dados de Pereira et al., (2002). Osório et al., (1999a) relatam valores semelhantes, à exceção do fígado, onde os animais não castrados apresentaram peso maior do que os castrados $(\mathrm{P}<0,10)$. Dados similares foram apresentados por Pereira et al., (2002), à exceção do peso do fígado $(\mathrm{P}<0,05)$ e dos rins $(\mathrm{P}<0,10)$ que foi superior nos animais não castrados.

A média e o desvio padrão para o rendimento verdadeiro (\%) e comercial (\%) foram de 47,3 $\pm 2,74$ e 45,2 $\pm 4,01 \quad(\mathrm{P}>0,05)$, respectivamente. Osório et al., (1999a), encontrou rendimento verdadeiro e comercial superior nos animais castrados em comparação com os não castrados $(\mathrm{P}<0,05)$, em função da maior quantidade de gordura interna e de carcaças mais engorduradas. Bonacina et al., (2007), também não encontraram diferenças no rendimento de carcaça, entre fêmeas, machos castrados e não castrados, entre animais de diferentes genótipos (Ideal, Corriedale x Texel e Corriedale x Hampshire Down).

A compacidade média foi de $0,50 \pm 0,08$ $(\mathrm{P}>0,05)$, enquanto que a altura nas cruzes, nas pernas, peso da cabeça, de patas, do pelego, do coração, dos rins, do fígado e da língua também 
não apresentaram diferença significativa entre os tratamentos $(\mathrm{P}>0,05)$.

Os índices de composição da cor L*, a* e b* não apresentaram diferenças entre os tratamentos $(\mathrm{P}>0,05)$ (Tabela 3), e são similares aos valores citados na bibliografia para carnes vermelhas, porém com valores absolutos maiores, provavelmente em função da utilização da paleta ao invés do músculo Longissimus dorsi, como na maioria dos trabalhos. Os valores para luminosidade ( $\mathrm{L}^{*}$ ) variaram de 40,68 a 51,35 enquanto que, os valores para intensidade da cor vermelha $\left(a^{*}\right)$ e cor amarela $\left(b^{*}\right)$ variaram de 10,78 a 25,60 e 12,01 a 18,22 respectivamente.

Osório et al., (1999b), também não encontraram diferenças na cor da carne de cordeiros Corriedale castrados $(2,3 \pm 0,5)$ e não castrados $(2,1 \pm 0,4)$, quando avaliadas através de uma escala subjetiva.

Rota et al., (2006), relataram que a carne de cordeiros castrados apresentaram maior luminosidade quando comparado com os não castrados, diferentemente de outros autores que não encontraram diferenças entre machos, fêmeas e criptorquidas.

Siqueira, Simões e Fernandes (2001), não encontraram efeito do sexo de cordeiros mestiços Ile de France x Corriedale abatidos em quatro pesos distintos, sobre as características da caraça, mas houve um aumento na espessura de gordura com o aumento da idade dos animais.

Crouse et al., (1981), relataram que os cordeiros inteiros apresentaram um crescimento mais rápido, carcaças mais pesadas, maior área de lombo quando comparado com os castrados, ocorrendo o inverso, para a cor da gordura mais amarelada e para o depósito de gordura na pélvis e fígado.

Oliveira, Osório e Monteiro (1998), em estudos com cordeiros das raças Texel, Romney Marsh, Corriedale, Ideal e Merino, criados em pastagem nativa e suplementados com $200 \mathrm{~g}$ de concentrado por cabeça.dia ${ }^{-1}$, encontraram maior peso de carcaça para os cordeiros Texel seguidos pelos Romney, sendo as demais carcaças semelhantes $(\mathrm{P}>0,05)$.
Neste mesmo trabalho, as carcaças dos cordeiros Romney, Corriedale e Merino apresentaram menor gordura e apresentaram os menores escores de engraxamento. Os cordeiros da raça Texel tiveram a menor percentagem de osso e a maior de músculo $(\mathrm{P}<0,05)$, e entre os diferentes genótipos, não houve diferenças na gordura da paleta $(\mathrm{P}>0,05)$.

Ribeiro et al., (2001), trabalhando com 24 cordeiros, sendo oito inteiros e oito castrados da raça Ile de France e oito castrados da raça Hampshire Down, criados em pastagem nativa e abatidos aos 12 meses de idade, não encontraram diferenças entre animais inteiros e castrados. Porém observaram diferenças na composição tecidual da paleta entre as raças, sendo que os animais da raça Ile de France apresentaram maior percentual de músculo e maior relação músculo/osso quando comparados com os Hampshire Down.

Bianchi et al., (2006), compararam o efeito do peso ao sacrifício, cordeiros levianos versus pesados, sobre a qualidade da carcaça e da carne de 24 fêmeas, 23 machos criptorquidas e 19 cordeiros castrados da raça Corriedale puros, Hampshire Down x Corriedale e Southdown x Corriedale. O peso ao sacrifício afetou todas as características da carcaça avaliadas $(\mathrm{P}<0,05)$. Os cordeiros pesados apresentaram melhor conformação, superior grau de engraxamento e composição tecidual mais favorável. Entretanto, as carcaças dos cordeiros levianos apresentaram um melhor rendimento comercial de cortes nobres que as dos cordeiros pesados. Sensorialmente, o sexo do cordeiro e o tipo genético resultaram em carne mais macia nas fêmeas e castrados quando comparados com os criptorquidas.

\section{Conclusão}

Não há diferenças entre a produção, os componentes e as características da carne e da carcaça ovina produzida por cordeiros não castrados, castrados e induzidos ao criptorquidismo criados em condições de pastagem nativa e abatidos jovens. 


\section{Agradecimentos}

Os autores agradecem às pessoas e instituições que, direta ou indiretamente, colaboraram para a execução deste trabalho e, em especial, à Secretaria de Ciência e Tecnologia do RS, através do Programa Pólos de Inovação Tecnológica.

\section{Referências}

AZEREDO, D. M.; OSORIO, M. T. M.; OSORIO, J. C. S.; MENDONÇA, G.; ESTEVES, R. M.; JARDIM, R. D.; POUEY, J.; BARBOZA, J. Componentes corporais em ovinos corriedale não castrados, castrados e criptorquidas abatidos em diferentes idades. Revista Brasileira de Agrociências, Pelotas, v. 11, n. 3, p. 333-338, 2005.

AZZARINI, M.; GAGGERO, C.; CASTELLS, D.; CARDELlinO, R. Efeito de la castración, de la criptorquidia inducida y de la dotación, sobre el crecimento y la producción de carne de corderos pesados "Tipo Sul" en pasturas sembradas. Producción Ovina, Montevideo, v. 14, p. 25-34, 2001.

BEERMANN, D. H.; ROBINSON, T. F.; HOGUE, D. E. Impact of composition manipulation on lean lamb production in the United States. Journal of Animal Science, Champaign, v. 73, n. 8, p. 2493-2502, 1995.

BIANCHI, G.; GARIBOTTO, G.; FEED, O.; BENTANCUR, O.; FRANCO, J. Efecto del peso al sacrifício sobre la calidad de la canal y de la carne de corderos corriedale puros e cruzas. Archivos de Medicina Veterinária, Valdivia, v. 38, n. 2, p. 161-165, 2006.

BONACINA, M.; OSORIO, J. C. S.; OSORIO, M. T. M.; ESTEVES, R.; JARDIM, R.; MENDONÇA, G.; OLIVEIRA, M. Otimização da avaliação in vivo e da carcaça em cordeiros. Revista da FZVA, Uruguaiana, v. 14, n. 1, p. 273-286, 2007.

CARVALHO, S.; PIRES, C. C.; PERES, J. R. R.; ZEPPENFELD, C.; WEISS, A. Desempenho de cordeiros machos inteiros, machos castrados e fêmeas, alimentados em confinamento. Ciência Rural, Santa Maria, v. 29, n. 1, p. 129-133, 1999.

CROUSE, J. D.; BUSBOOM, J. R.; FIELD, R. A.; FERRELL, C. L. The effects of breed, diet, sex, location and slaughter weight on lamb growth, carcass composition and meat flavor. Journal of Animal Science, Champaign, v. 53 , n. 2 , p. 376-386, 1981.
INSTITUTO BRASILEIRO DE GEOGRAFIA E ESTATÍSTICA- IBGE. Sistema IBGE de recuperação automática - SIDRA. IBGE, 2009. Disponível em: $<$ http://sidra.ibge.gov.br>. Acesso em: 10 mar. 2009

KLEIN JR., M. H.; SIQUEIRA, E. R.; ROÇA, R. O. Composição tecidual e qualidade da gordura na carne de cordeiros castrados e não castrados confinados sob dois fotoperiodo. Arquivo Brasileiro de Medicina Veterinária e Zootecnia, Belo Horizonte, v. 60, n. 2, p. 461-469, 2008.

OLIVEIRA, M. O.; OSORIO, J. C. S.; MONTEIRO, E. M. Produção de carne em ovinos de cinco genótipos. 4. Composição regional e tecidual. Ciência Rural, Santa Maria, v. 28, n. 1, p. 125-129, 1998.

OSÓRIO, J. C. S.; JARDIM, P. O. C.; PIMENTEL, M. A.; POUEY, J.; OSORIO, M. T. M.; LÜDER, W. E.; BORBA, M. F. Produção de carne entre cordeiros castrados e não castrados. 1. Cruzas Hampshire Down x Corriedale. Ciência Rural, Santa Maria, v. 29, n. 1, p. 135-138, 1999a.

OSÓRIO, J. C. S.; OSÓRIO, M. T. M.; FARIA, H.; PIMENTEL, M. A.; POUEY, J.; ESTEVES, R. Efeito da castração sobre a produção de carne de cordeiros corriedale. Revista Brasileira de Agrociências, Pelotas, v. 5 , n. 3 , p. $207-210,1999$ b.

OSÓRIO, J. C.; OSÓRIO, M. T.; JARDIM, P. O.; PIMENTAL, M.; POUEY, J. L.; LÜDER, W. E.; CARDELINO, R. A.; OLIVEIRA, N. M.; GULARTE, M. A.; BORBA, M. F.; MOTTA, L.; ESTEVES, R.; MONTEIRO,E.;ZAMBIAZI, R. Métodos para avaliação da produção de carne ovina: in vivo, na carcaça e na carne. Pelotas: UFPel, 1998, $107 \mathrm{p}$.

PEREIRA, P. H. S.; OSORIO, J. C. S., OSORIO, M. T. M.; OLIVEIRA, N. M.; FARIA, H.; PIMENTEL, M. A. Componentes do peso vivo em cordeiros castrados e não castrados. Revista Brasileira de Agrociências, Pelotas, v. 8, n. 1, p. 57-60, 2002.

RIBEIRO, E. L. A.; ROCHA, M. A.; MIZUBUTI, Y; SILVA, L. D. F.; RIBEIRO, H. J. S. S.; MORI, R. M. Carcaça de borregos Ille de France inteiros ou castrados e Hampshire Down castrados abatidos aos doze meses de idade, Ciência Rural, Santa Maria, v. 31, n. 3, p. 479482, 2001.

RIBEIRO, E. L. A.; SILVA, L. D. F.; ROCHA, M. A.; MIZUBUTI, I. Y. Desempenho de cordeiros inteiros ou submetidos a diferentes métodos de castração abatidos aos $30 \mathrm{~kg}$ de peso vivo. Revista Brasileira de Zootecnia, Viçosa, v. 32, n. 3, p. 745-752, 2003. 
ROCHA, H. C.; FONTANELI, R. S.; PICOLOTTO, F.; VIEIRA, M. I. B.; CECCHETTI, D.; NADAL, R. P.; ROCHA, F. S.; MULLER, G. Características da carne de cordeiro produzido em campo nativo do sul do Brasil. Archives of Veterinary Science, Curitiba, v. 12, p. 178179, 2007. Suplemento.

ROCHA, H. C.; DICKEL, E. L.; MESSINA, S. A. Produção de Cordeiro de Corte em Sistema de Consorciação. 2. ed. Passo Fundo: UPF, 2007. 76 p.

ROTA, E. L.; OSORIO, M. T. M.; OSORIO, J. C. S.; OLIVEIRA, M. M.; WIEGAND, M. M.; MENDONÇA, G.; ESTEVES, R. M.; GONÇALVES, M. Influência da castração e da idade de abate sobre as características subjetivas e instrumentais da carne de cordeiros Corriedale. Revista Brasileira de Zootecnia, Viçosa, v. 35, n. 6, p. 2397-2405, 2006.

SILVA SOBRINHO, A. G. Criação de ovinos. 3 ed. rev. e ampl. Jaboticabal: FUNEP:UNESP. 2001. 230 p.

SIQUEIRA, E. R.; SIMÕES, C. D.; FERNANDES, S. Efeito do sexo e do peso ao abate sobre a produção de carne de cordeiro. Morfometria da carcaça, pesos dos cortes, composição tecidual e componentes não constituintes da carcaça. Revista Brasileira de Zootecnia, Viçosa, v. 30, n. 4, p. 1299-1307, 2001. 
